\title{
Determining Practices Achievement in the Requirement Management Process Using a Two-Stage Questionnaire
}

\author{
Gonzalo Cuevas \\ Facultad de Informática \\ Universidad Politécnica \\ de Madrid \\ gcuevas@fi.upm.es
}

\author{
Ariel Serrano \\ Facultad de Informática \\ Universidad Politécnica \\ de Madrid \\ aserrano@zipi.fi.upm.es
}

\author{
Alan Serrano \\ Department of Information \\ Systems \& Computing \\ Brunel University \\ alan.edwin.serrano-rico@brunel.ac.uk
}

\begin{abstract}
This paper aims to obtain a baseline snapshot of the requirement management process using a two-stage questionnaire to identify both performed and nonperformed CMMI practices. The questionnaire proposed in this paper may help with the assessment of the requirement management process, provide useful information related to the current state of the process, and indicate those practices that require immediate attention with the aim of begin a Software Process Improvement program.
\end{abstract}

\section{Introduction}

Nowadays, a movement based on the Software Process Improvement (SPI) principle is being established with solid, positive, and lasting results From this movement emerge some of "Best Prachices Reference Models" These practices are called best practices because some institutions have collected practices from organizations which have reached outstanding results in their software process. The practices are organized into processes and a reference model is a set of processes that guides organizations to improving their software quality. The most known and extended model in the software community is the Capability Maturity Model (CMM) [1]

This research advocates the idea that although requirement management is not carried out in many organizations there are isolated members or groups that perform their own Requirement Managenent (RM) practices. These practices, however, are usually not documented and as a consequence are not spread across the organization

Despite the fact the CMM describes the best practices to improve a RM process in an organization; there is little research in relation to how implement it and how to appraise it In order to start an SPI program the first step is to appraise the state of the current practices [2]
The objective of this paper is to provide a data collection instrument for the assessment of the RM process, so you may get an accurate picture of your organization's RM process. It is expected with the use of the questionnaire may provide useful information related to the current state of the RM process and identify which RM practices are performed but not documented, which need more attention and which are not implemented due to bad management or unawareness

The data derived from the questionnaire may help to identify some best RM practices and they could be useful to improve the organizations software quality. Besides, the questionnaire may be used as a data collection instrument for a more extensive assessment method such as SCAMPI[3]

\subsection{The CMMI background}

The Software Engineering Institute (SEI) develop a process maturity framework that would help organizations improve their software process [2] After four years of experience with the framework, the work initiated by Humphrey, derived into the Capability' Maturity Model for Software (SW-CMM) [1] With the success of this model, other disciplines start developing capability maturity models in areas such as systems engineering, software acquisition, workforce management, and integrated product and process development The use of multiple models, however, was problematic, mainly because many organizations have to divide their improvement efforts across different models

The CMMI was developed to solve the problem of using multiple CMM models. The CMMI was developed integrating practices from four different source models for software (SW-CMM), for systems engineering (SECMM), for integrated product development (IPD-CMM). and for acquisition (EIA-731)

The CMMI has two representations: Staged [4] and Continuous [5] The staged representation provides a 
frantework to organize the process improvement sieps into tive maturity levels. These levels define an ordinal scale for measuring the maturity of an organization's softwarc process and hetp the organization to proritize its improvement efforts. The continuous representation is organized into capability levels similar as a maturity levels. The main difference between previous representation and this one is that the improvement efforts could be focuses at any process area of the organization without following a process sequence.

\subsection{The Requirement Management Process}

It is generally accepted that requirements are the foundation upon which the software engineering process is built. It is also argued that unclear requirements and the inability to manage changing requirements may cause must of the customer dissatisfaction and may erode profits [6]. Requirements are eliciled by the customers, soffware engineers, or both and are the basis for all program plans and activities. Complete, concise, and clear requirements will give the software engineerng a precise baseline with which to build the sof tware system.

A good requirement should be traceable to business objectives and should be related to system lifecycle componeris. It should be consistent with the scope and constrain of the product, incorporale stakeholder expectations, should be measurable against acceptance critera, and should be maintainable over the producl"s lifecycle [7]. Since software application complexity has increased, however, it is more dilficull to clearly determine requirements at the beginning of software systems lifecycle. The Requirements Management (RM) process emerges as at syslematic appoach to lind, document, organise, and track all system's requirements RM major ain is to establsh a comnon understanding between the requirement providers and the sofware cngineering projecl tean. A quality $\mathrm{RM}$ process is fundamental [or a success[u] software enginecring process. It is very unikely that a poor comprehension of the requirements can lead to a salisfying product.

$\mathrm{RM}$ has bees selected because requirements are considered the comerstone of the soltware lilecycle and because requirements elictation is the first slep of the soltware development process There is evidence that suggests that a deficient RM nlay be onc of the principal causes of many problems related to the further stages in the software development process [6].

This paper is divided into four main sections. Section 2 presents the critique of some data collection instruments used for the assessment in some Software Process Improvement (SPI) projects found in the literature. Section 2 establishes the rationale for the questionnaire and its structure. Section 4 presents the conclusions of this paper and points at future research activities.

\section{A critique of some questionnaires used for the software process assessment}

There are a wide number of data collection instruments that can be used for assessment: questionnaires, surveys, interviews, and reviewing documentation, all having their advantages and disadvantages One of the techniques that are most commonly used is questionnaires. This is mainly because they can be applied to many people, is cost effective, non-invasive, provides quantitative data, and is possible to analyze the results with promptness [8].

Questionnaires can be classified in into open and close questions. An open-question provides more information than a close one. The complexity for the analysis of the data provided by open questions, however, is higher than those in closed-questions [9]. On the other hand, a closedquestion provides less information but it is easier to analyze its results and these are obtained faster than the open one

Consequently, for this research a questionnaire was developed using a closed question as a main instrument to collect data appraisal. It has been argued that the application of questionnaires consumes less time, effort and financial resources than other methods of data collection such as interviews and document reviews [10]. Hence this technique has been lound suitable for this research

\subsection{Review of some questionnaires used for the software process assessment}

In order to propose a new instrument to collect data assessment, a review of the questionnaires available in the literature was performed. The first questionnaire reviewed was the SEI's Maturity Questionnaire [11]. The major disadvantage of this questionnaire is that it was developed for the SW-CMM model and therefore, cannot be applied as it is, to the CMMI model. Also the maturity questionnaire provides a little information about the RM process because it focuses on the maturity of the process and does not centre of attention to find the weakness of the practices

Another disadvantage is that this questionnaire is limited on the number of responses that can be selected: Yes, No, Does not Apply and Don't Know. In fact, there are only two options Yes and No because Does not Apply and Don't Know are used to validate the application of the questionnaire. Using the maturity questionnaire limits the information to two extreme ends: Yes, if the practice is performed and No if the practice is not performed. Therefore, it does not leave room for intermediate points. For example, there are not options to capture the cases where the practices are performed but rarely documented 
or when they are not documented at all. This type of questions cannot be addressed with the options provided in the Maturity Questionnaire

Questionnaires with limited answer options may provide limited or misleading information. For example a project sponsored by the SEI "CMMI Interpretive Guidance Project" support this argument. The questionnaire was applied to more than 600 people and the results report the following:

"We are not providing the results of the Generic Goals and Practices and Specific Process Areas sections of the Web-based questionnaire in this preliminary report. In both of these sections, there were no radio buttons and therefore the responses provided were in the form of specific comments. Many of these specific comments contain little information. For example, responses such as 'none 'or 'no' were common" [12].

In the same project, however, the SEI used, in onequestion, five possible responses: Almost always, More often than not, Sometimes, Rarely if ever and Don't know. As a result more distributions of the type of responses were obtained (See Figure 1). The report does not explain, however, the reasons of why this methodology was not used in the same way for specific and generic practices questions

In the report of the Process Improvement Program for the Northrop Grumman Information Technology company [13] proposes a Questionnaire-Based Appraisals with seven possible responses: Does Not Apply, Don't know, No, About 25\% of the time, About $50 \%$ of the time, About $75 \%$ of the time, and Yes. This work proposes more responses granularity, however, does not explain how apply this questionnaire to the RM process. Another disadvantage is that this report was used the SA-CMM as a reference model and it focuses on the Software Acquisition process

Another work reviewed was the software improvement model proposed by the Institute for Software Process Improvement. This model was used by Calvo-Manzano in their researches [14]. They proposed for the appraisal stage a questionnaire sucture using live types of responses: Always when the practice is documented and performed between $100 \%-75 \%$ of the times More offer when the practice is documented and performed between $75 \%-100 \%$ of the times. Sometimes when the practice is not documented and is performed between 100\% - 25\% of the times. Rarely when the practice could be documented or not and it is performed between $25 \%->0$ of the times. Never when the practice is not performed in the organisation. The responses granularity is similar to Marciniak and Sadauskas [13] and provides more information about the current state of the practices. This work only provides general information about the process without covering full detail of the RM process and without proposing precise actions to the process improvement. Moreover, this questionnaire was designed for SW-CMM.

In summary, the questionnaires reviewed here are deficient in their design and do not obtain relevant information mainly due to the fact that were designed with very limited number of responses Furthermore, there is not evidence of a questionnaire that address in detail the RM process and there is not evidence of a questionnaire that covers both generic and specific practices of the CMMI.

\section{An alternative data collection instrument: the two-stage questionnaire}

We develop a two-stage questionnaire using closed questions and limit the number of possible responses to seven. These are organised as follows:

- Five level-perform-answers: Almost Always, More often than not, Sometimes, Rarely if ever, and Never. These will allow knowing the extent to which each practice is performed.

- Two validity-answers: Don't Know and Not Apply. These will be used to appraise the validation of the questions. To validate the correctness of the question. And to check the syntaxes of the question.

Additional information spaces (Comments) to extract supplementary background information. It is mandatory to write any comments when check any of the validityanswers. Each possible response has a unique interpretation and indicates the performing level of a requirement management practices as is described in following Table 1:

\begin{tabular}{|c|c|}
\hline Almost Always & $\begin{array}{l}\text { The practice should be performed almost } \\
\text { always in order to be considered well } \\
\text { established as a standard operating } \\
\text { procedure, moreover, it should be well } \\
\text { documented and performed between }>=75 \\
\text { and } 100 \text { percent of the organization's } \\
\text { projects. }\end{array}$ \\
\hline $\begin{array}{l}\text { More often than } \\
\text { not }\end{array}$ & $\begin{array}{l}\text { The practice should be performed more often } \\
\text { than not between }>=50 \text { and } 75<\text { percent of } \\
\text { the organization's projects, and it sometimes } \\
\text { is documented. }\end{array}$ \\
\hline Somotimes & $\begin{array}{l}\text { The practice may be performed sometimes } \\
\text { between }>=25 \text { and } 50<\text { percent of the } \\
\text { organization's projects, and it usually is not } \\
\text { documented. Some groups have intention to } \\
\text { perform the practice but non-sponsorship }\end{array}$ \\
\hline Raraly if over & $\begin{array}{l}\text { The practice may be performed rarely if ever } \\
\text { between }>0 \text { and } 25<\text { percent of the } \\
\text { organization's projects, and is not } \\
\text { documented. Only some insolate people has } \\
\text { intention to perform the practice }\end{array}$ \\
\hline Novor & $\begin{array}{l}\text { The practice never is performed at any } \\
\text { organization's projects. Nobody has intention } \\
\text { to improve the eractice }\end{array}$ \\
\hline Don't Krow & $\begin{array}{l}\text { The question is not clear, is ambiguous, or } \\
\text { you do not know how some lerminology is } \\
\text { used. It is mandatory to write on the }\end{array}$ \\
\hline
\end{tabular}




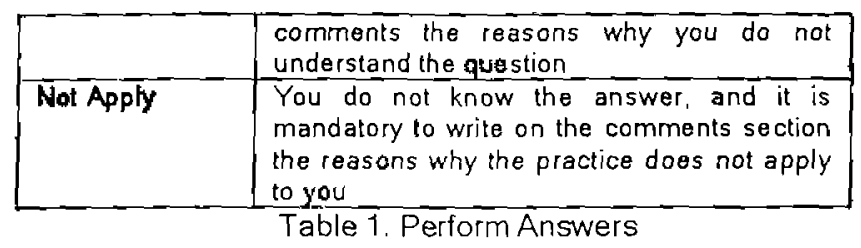

Level-perform answer values vary from 'Never' with a value equal to 0 , 'Rarely if ever' with a value equal to 1 , 'Sometimes' with a value equal to 2, and 'More often than not' with a value equal to 3 , and 'Almost Always' with a value equal to 4 The validity answers do not have a numeric value.

\subsection{Questionnaire structure: the two-stage division}

The questionnaire proposed here was based on the two types of practices establish by the CMMI and it is divided into two stages. The first-stage is related to the specific practices and the second-stage to the generic practices Another reason of this division is to differentiate the type of audience to whom it is applied

The first-stage is aimed at the employees that execute the process, and it is based on the specific practices from Requirement Management Process Area (REQM) of the CMMI $[4,5]$. This stage is divided into five practices that will be performed to have a well established RM process

- Obtain an Understanding of the Requirements with the users and clients

- Obtain Commitment to Requirements of all the participants of the project

- Manage Requirements Changes during the project lifecycle

- Manage requirements traceability follow the life of a requirement in both a forwards and backwards direction

- Find the inconsistencies to could exist between the project plans and the soliware requirenuents and taking corrective actions when necessary

The second-stage is aimed at the higher-level managetnent such as gurvernl matnager, system maniget. soliware manager, or team leader, and it is based on the generic practices from the REQM of the CMMI $[4,5]$ The application of this stage ainss to find those activities for managing the allocaled requrements are institutionalized or nol and if they can support it repeatable process. A repeatable process is a sel of activities performed to achieve a given purpose that naaintains and controls the requirement management process in a constant form [or all organisations project To determine if a RM process is institutionalised, If is necessary to perform the following activities:

- Adhering to organisational policjes

- Tracking a documented projeci plan
- Allocating adequate resources

- Assigning responsibility and authority

- Training the affected people

- Placing under version control or configuration management

- Reviewed by the people those affected

- Measuring the process

- Compliant the process with specified standards

- Reviewing status with higher-level mangement

It is expected that the cross analysis of the responses of both questionnaires can allow to know those RM practices that have been covered by the software team and that have been spread throughout the organisation as an institutionalised process. Similarly, this cross analysis can help to identify other issues related to the combination of the parameters of both stages of this questionnaire.

If you require a copy of the complete two-stage questionnaire, then please do not hesitate to contact us

\section{Conclusions and further research}

The CMM is considered as one of the most known models that focus on software process improvement to achieve quality software Nevertheless the CMMI is relatively new, so there is not much research written about which data collection instruments can be used using the CMMI approach Therefore, this research developed an instrument to evaluate the current status of requirement management practices The data collection instrument developed to the assessment is a two-stage questionnaire.

This questionnaire is divided into two stages: one to identify specific practices and the second to identify' generic practices. In this way this questionnaire matches the needs of the CMM since these differences are identified. Furthermore, this division also helps to differentiate the roles of the employees. For instance, the first-stage refers to the series of steps that have to be followed to perform the requirement management process and it applies to those employees that execute the requirement management process. The second-stage refers to the maturity and institutionalization of the requirement management process and in applies to the employees that manage the process. This differentiation based on the idea that the questions that are applied to the process executers are not relevant to the process managers and vice versa. Therefore, by dividing the questionnaire into two stages the problem of addressing the wrong people is minimised.

Applying the two-stage questionnaire to the RM process firstly, will provide valuable information telates to those areas that require more attention. Secondly, I will reduce the cost, time and effort of the assessmen because the enquirer can identify only witch employee should be interviewed in a second evaluation round. An. finally, it will use as a data collection instrument for 
more extensive assessment method like SCAMPI [3]. Moreover, developing techniques and tools to implement software process improvement programs based on the CMMI will allow this framework to reach, not only big organisations, but also a wider audience including small and medium enterprises so they can take the advantages provided by the CMMI. It is expected that this research will provide a wider vision of the current status of the organization's Software development process

Besides, appraising the state of the current practices is the first step to implement a Software Process Improvement program in an organisation. So our next research efforts will focus on the validation of the twostage questionnaire in a case study.

Nevertheless most of the literature has focused on what practices need to be implemented to improve a give process but has barely focused on explaining how to implement these practices [15]. The identification of only what practices need to implement is not sufficient and the descriptions steps of how to implement it is also required for a successful Software Process Improvement program. In the same way our future research will be concentrated on developing a methodology to implement the CMMI practices for the requirement management process.

\section{References}

[1] M Paulk, B Curtis, M.B. Chrissis, and C.V. Weber, "Capability Maturity Model ${ }^{\circledR}$ for Software, Version 1.1," CMU/SEI-93-TR-024, Software Engineering Institute, Camegie Mellon University, February 1993.

[2] W.S Humphrey, "Characterizing the software process: a maturity framework," IEEE Software, vol. $5, \mathrm{pp} 73 \cdot 79,1988$

[3] Members of the Assessment Method Integrated Team, "Standard CMMI ${ }^{\infty}$ Appraisal Method for Process Improvement (SCAMPI), Version 1.1," CMU/SEI2001-HB-001, Software Engineering Institute, Camegie Mellon University, December, 2001.

[4] CMMI Product Development Team, "Capability Maturity Model $^{\circledR}$ Integration (CMMI ${ }^{\circledR}$ ), Version 1.1, Staged Representation," CMU/SEI-2002-TR-012, Software Engineering Institute, Carnegie Mellon University, March 2002

[5] CMMI Product Development Team, "Capability Maturity Model ${ }^{\Phi}$ Integration $\left(\mathrm{CMMI}^{\Phi}\right)$, Version 1.1, Continuous Representation," CMU/SEI-2002-TR-011, Software Engineering Institute, Carnegie Mellon University, March 2002

[6] [ Sommerville and P. Sawyer, Requirements Engineering: A good practice guide. England: John Wiley \& Sons, 1997.

[7] R. Hadden, "How Scalable Are CMM Key Practices?," CrossTalk The Journal of Defense Software Engineering, pp. 18-23, 1988.

[8] B. Gillham, Developing a Questionnaire. London ; New York: Continuum, 2000.
[9] K. Yamarishi and H. Li, "Mining Open Answers in Questionnaire Data," IEEE Intelligent Systems, vol. 17, pp. $58-63,2002$.

[10] P. Brewerton, Organizational research methods. London: SAGE, 2001.

[11] D. Zubrow, W. Hayes, J Siegel and D. Goldenson, "Maturity Questionnaire," CMU/SEI-94-SR-7, Software Engineering Institute, Carnegie Mellon University, June 1994

[12] M. Chrissis, G. Wemyss, D. Goldenson, M. Konrad, K. Smith, and A. Svolou, "CMMI Interpretive Guidance Project: Preliminary Report," CMU/SEI2003-SR-007, Software Engineering Institute, Carnegie Mellon University, October 2003.

[13] J. J. Marciniak and T. Sadauskas, "Use of Questionnaire-Based Appraisals in Process Improvement Programs," presented at Second Annual Conference on the Acquisition of Software-Intensive Systems, Arlington, Virgiria, USA, 2003.

[14] J. A. Calvo-Manzano, G. Cuevas, T. San-Feliu, A De-Amescua, L. García, and M. Pérez, "Experiences in the Application of Software Process Improvement in SMES," Software Quality Journal, vol 10, pp 261 $-273,2002$

[15] M. Niazi, D. Wilson, and D. Zowghi, "A maturity model for the implementation of software process improvement: an empirical study," The Journal of Systems and Software, pp. In Press, Corrected Proof, 2003. 